Research Article

\title{
Survey Based Evaluation of Mental Health of Students Pursuing Higher Education
}

Shailee H. Patel ${ }^{1 *}$, Chinmay H. Jain ${ }^{1}$, Aman A. Mody ${ }^{1}$, Anas A. Jamsa², G. S. Chakraborthy ${ }^{3}$, Snigdha D. Mandal², Jagdish Kakadiya², Mohit D. Buddhadev²

1. Parul Institute of Pharmacy and Research, Parul University, Gujarat, India.

2. Department of pharmacology, Parul Institute of Pharmacy and Research, Parul University, Gujarat, India.

3. Parul Institute of Pharmacy and Research, Parul University, Gujarat, India.

*Corresponding author's E-mail: shaileepatel07@gmail.com

Received: 17-10-2021; Revised: 08-12-2021; Accepted: 16-12-2021; Published on: 15-01-2022.

\section{ABSTRACT}

Academic and non-academic institutions have different working style and environment, therefore there is difference in symptoms, reasons, and consequences of stress. According to World Health Organization report, practically about $10 \%$ of the students of any institution of higher learning are very likely to have emotional problems at some point of time which interferes seriously with their work. The relationship between university and stress is reported by students worldwide. The objective of the study is to identify psycho-social factors associated with mental health in students of higher education. An online study that was designed using Google forms and link was sent through social media platforms. Age was categorized in 17-18, 19-20, 21-22 and Above 22 categories. Total of 447 students participated where 191 were females $(42.7 \%)$ and 256 were males (57.3\%). The age ranges from $17-25$ years with an average age of 21 years. Upon analysis it was found that $9.6 \%$ of the students had thought about suicide at least once When the data was analyzed categorically it was found that the age group 17-18 was the group most venerable to suicidal thoughts and the age group Above 22 was the least venerable to suicidal thoughts.

Keywords: Mental Health, Stress, Depression, Anxiety, University Students.

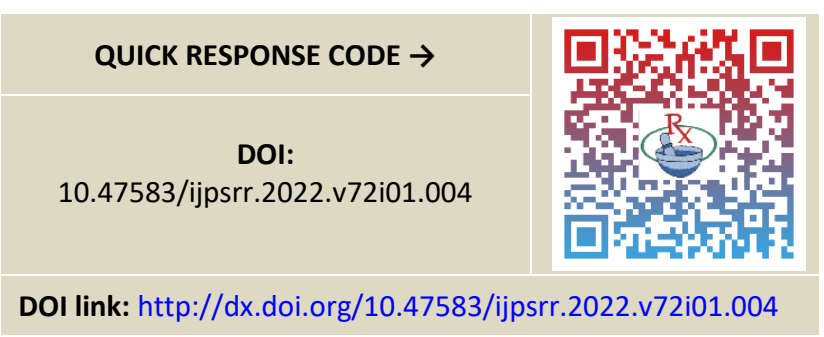

\section{INTRODUCTION}

ndia has one of the largest education systems in the world. Stress may produce different consequences if not managed well. Stress appears to be very common in college students' life. They have to manage a persona and have to prepare themselves for further graduate or professional training. Our education system has gradually evolved into a race, where the ethos of learning has been stripped down to a mere game of scoring marks. We are oblivious of the thousands of dreams that could not be fulfilled due to the pressure and stress inflicted on the students because of the so-called race, and it affects the life of thousands of students, and it requires a study of the impact of stress on the mental health of the students ${ }^{1}$. According to WHO (World Health Organization) report, practically about $10 \%$ of the members of any institution of higher learning are very likely to have emotional problems at some time or the other which interferes seriously with their work ${ }^{2}$. The inability to cope successfully with tremendous stress of education may lead to a cascade of consequences at both a personal and professional level. Stress has been shown to have deleterious effects on a person's physical and mental well-being ${ }^{3}$. The relationship between university and stress is reported by students worldwide. One in five students strongly felt the need to hide their mental or emotional problems, and the reasons given by students include; feeling there was no need to, concerns they would not be believed, fears of being discriminated against, judged or stigmatized, concerns of privacy and confidentiality being breached, embarrassment and previous negative experiences ${ }^{4}$. So, the role of screening becomes important. Unfortunately, excessive stress can then potentially become unrecognizable, by students and professionals alike, until the effects of professional burnout become all too apparent. University students are unique group of people that are going through a critical transitional period in which they are going from adolescence to adulthood and it can be the most stressful times of a person's life. Often the causes of anxiety for a lot of students are related to trying to fit in, maintain good grades, plan for the future, and may be away from home ${ }^{5}$. As a reaction to this, students might get depressed. They may isolate themselves, skip classes, or cry all of the time without realizing they are depressed. Previous studies reported that the prevalence of depression in university students seems to be increasing ${ }^{6}$. Over two-thirds of young people do not talk about or seek help for mental health problems ${ }^{7}$. According to the WHO, a person can be termed depressed if shows a variable combination of loss of interest or pleasure, feelings like guilt, hopeless and restless, low mood, low self-esteem, disturbed sleep, disturbed concentration and disturbed appetite ${ }^{8}$. Different research studies have mentioned 
different reasons behind student's stress and depression. Low financial support and the level of academic year were significantly associated with stress among nursing students 9. Stigmatizing attitudes about depression and mental health services may become a barrier to seeking help and support. The most frequent barriers to using these services in a qualitative study were lack of time and confidentiality, the stigma associated with mental health services utilization, cost of treatment, fear of documentation on academic record, and fear of unwanted intervention ${ }^{10}$.

AIM: The aim of this study is to assess mental health of students pursuing higher education.

\section{MATERIALS AND METHODS}

\section{Study Preparation}

An Observational study was designed to determine the mental health of students perusing higher education.

\section{Data Collection}

The data was collected from the students from different universities of India through the online platform of Google forms; the link of the questionnaire was distributed through social media platforms such as WhatsApp, Facebook \& Instagram.

\section{Sample Selection Criteria}

The survey was constructed for students who were pursuing higher education, therefore only the students who were pursuing higher education and were willing to participate were included. The data was collected from 21th Aug 2020 to 9th Feb 2021. The data collected was calculated using Microsoft Excel Software and Statistical Package for the Social Sciences (SPSS) Software.

\section{Data Analysis and Statistical Application}

The data collected were comprised of questions pertaining to the student's mood, their interest, their relationships and their physical wellbeing.

\section{RESULTS AND DISCUSSION}

Impairment in mental health appears to be a common issue in academic institutions. The Indian education system has evolved into a mere game of scoring marks ${ }^{1}$. Different research studies have mentioned the reasons behind students' depression and stress. One interesting institution based cross-sectional study was conducted by Manjot Singh and colleagues using the DASS- 21 method with a sample size of 400 students. The overall prevalence of depression, anxiety and stress were found to be $59.2 \%$, $86.5 \%$ and $52.7 \%$ respectively. It was also found that the prevalence of the DAS decreased with age and all the morbidity were more among females than males ${ }^{2}$.

Inability to cope with the stress of education may lead to several consequences at both personal and professional level ${ }^{3}$. Total of 447 students participated where 191 were females (42.7\%) and 256 were males (57.3\%). The age ranges from $17-25$ years with an average age of 21 years. According to the age criteria, they were divided into four categories those are 17-18, 19-20, 21-22 and Above 22.

Table 1: Demographic Details of respondents

\begin{tabular}{|l|c|c|c|c|}
\hline & & Frequency & Percent & Cumulative Percent \\
\hline Gender & Female & 191 & 42.7 & 42.7 \\
\hline Male & 256 & 57.3 & 100 \\
\hline Age & $17-18$ & 78 & 17.5 & 17.5 \\
\hline & $19-20$ & 179 & 40.1 & 57.6 \\
\hline & Above 22 & 136 & 30.4 & 88 \\
\hline 1st Year & 54 & 12 & 100 \\
\hline 2nd Year & 89 & 19.9 & 19.9 \\
\hline 3rd Year & 154 & 34.5 & 54.4 \\
\hline 4th Year & 83 & 18.6 & 72.9 \\
\hline 5th Year & 84 & 18.8 & 91.7 \\
\hline 6th Year & 34 & 7.6 & 99.3 \\
\hline & Total & 3 & 0.7 & 100 \\
\hline
\end{tabular}

University students in their transition to adulthood particularly suffer from challenges such as exploring or developing their identity, making career choices, creating social relationships in a different environment etc ${ }^{11}$. Not everyone who is depressed or manic may experience every symptom. The severity of symptoms may vary with the individual $^{12}$. Statistical evaluation of the data obtained from the students who had the problem of concentrating after 
starting the university stated that $4.25 \%$ of students always had the problem, $11.19 \%$ often had the problem, $56.15 \%$ students sometimes had the problem and $28.41 \%$ of students never had problem concentrating, Whereas Students who had problem memorizing things after starting the university education was found that $5.37 \%$ always had an issue, $13.87 \%$ often had an issue, $50.34 \%$ sometimes had an issue and $30.43 \%$ never had an issue.

Statistical evaluation of data obtained from the students who felt that they were less productive was found that $5.15 \%$ always had an issue, $14.77 \%$ often had an issue, $39.82 \%$ sometimes had an issue and $40.27 \%$ never had an issue. When the data was analysed categorically it was found that the age group 21-22 (5.1\%) had a maximum number of students with concentration issue and the age group Above 22 (37\%) was the group where the maximum number of students had no problem in concentrating, while the most responses where students thought that they were becoming less productive belonged to the age group 21-22 (5.9\%), Whereas the maximum number of students who did not believe in the above-mentioned premise were from the age group of Above 22 (42.6\%).

Feeling tired and uninterested in activities are some consequences of depression, Statistical evaluation of the data obtained from the students who felt more tired after starting the university education stated that $8.05 \%$ always had an issue, $15.44 \%$ often had an issue, $48.10 \%$ sometimes had an issue and $28.41 \%$ never had an issue and students who were less interested in socializing after starting the university education stated that $8.72 \%$ always had an issue, $15.66 \%$ often had an issue, $37.36 \%$ sometimes had an issue and $38.26 \%$ never had an issue. However, when students were asked about their interest in group activities $8.72 \%$ of students said that they were always less interested in group activities after starting the university education whereas $12.08 \%$ often had an issue, $35.57 \%$ sometimes had an issue and $43.62 \%$ never had an issue. Whereas statistical evaluation of data obtained from the students who were having difficulties in their relationships after starting the university education stated that $6.26 \%$ had a problem at both home or University/college, $4.47 \%$ had a problem only at home while $5.37 \%$ had a problem only at University/college. When the data was analysed categorically it was found that the age group 17-18 (11.5\%) had a maximum number of students who were less interested in group activities. While the most responses where students who had problems in their relationships belonged to the age group $19-20$ (8.4\%) whereas the maximum number of students who did not have any relationship issue belonged to the age group of Above 22 (83.3\%).

As a reaction to stress, students get depressed. They may cry all the time or isolate themselves without realizing they are depressed ${ }^{6}$. When participants were asked questions about their emotional wellbeing it was found that $61.74 \%$ of students had changes in their emotional wellbeing (6.71\% always had an issue, $17.45 \%$ often had an issue and
$37.58 \%$ sometimes had an issue) and $38.26 \%$ participants said that they had no changes in their emotional wellbeing. However, when the statistical evaluation of data obtained from the students who have been crying more than usual was done, it was found that $18.57 \%$ of the students had said yes, $75.84 \%$ students had said no and $5.59 \%$ students had said maybe.

Studies reported that stress affects the psychological health of students ${ }^{13}$. When students were asked about having mood swings after starting university education, $39.37 \%$ said that they were experiencing mood swings, $43.85 \%$ said that they were not experiencing mood swings and $16.78 \%$ said that they were not sure about experiencing mood swings. However, Statistical evaluation of data obtained from the students who were sadder after starting the university education stated that $6.26 \%$ always had an issue, $14.54 \%$ often had an issue, $40.04 \%$ sometimes had an issue and $39.15 \%$ never had an issue. Whereas when the evaluation of data obtained from the students who experienced mood changes when the weather changed was done and it was found that $34.90 \%$ had mood changes, $51.45 \%$ did not have mood changes and $13.65 \%$ were not sure about their mood changes. Statistical evaluation of data obtained from the students who felt that there was no joy in their life anymore stated that $17.45 \%$ of students felt that there was no joy in their life, $74.50 \%$ of students did not feel the same and $8.05 \%$ were not sure about their mood changes maybe. When the data was analysed categorically it was found that the age group 17-18 (50\%) had maximum number of students who experienced mood swings and the age group Above 22 (55\%) was the group where the maximum number of students did not experience mood swings. While the most responses where the students thought that they feel down when the weather changed were from the age group 17-18 (47.4\%) whereas the maximum number of students who did not believe in the above-mentioned premise were from the age group Above 22 (55.6\%).

It is reported that depression leads to various after-effects that may cause physical complications ${ }^{14}$. When the students were asked that if they had unusual pains after starting the university education, it was found that $3.13 \%$ always had an issue, $9.40 \%$ often had an issue, $33.56 \%$ sometimes had an issue and $53.91 \%$ never had an issue. However, statistical evaluation of the data obtained from the students who had a physical deformity/disability stated that $97.76 \%$ had no deformity/disability and $2.24 \%$ had a deformity/disability. When evaluation of data obtained from the students who feel that they are becoming slow at their daily work after starting the university education was done and it was found that $35.57 \%$ had an issue, $53.91 \%$ did not have an issue and $10.51 \%$ were not sure. Weight loss is also a common symptom of depression ${ }^{14}$. When statistical evaluation of data obtained from the students who experienced weight loss after starting the university education was done it was found that $66.89 \%$ had experienced no weight loss, $25.28 \%$ had experienced slight weight loss and $7.83 \%$ had experienced visible weight loss. 
When the data was analysed categorically it was found that the age group $21-22(9.6 \%)$ had the maximum number of students who had experienced visible weight loss.

Statistical evaluation of the data obtained from the students who were having a problem trusting people around them stated that $46.76 \%$ had a problem trusting people, $39.82 \%$ did not have a problem trusting people and $13.42 \%$ were not sure. However, evaluation of data obtained from the students who were facing problems with decision making stated that $37.36 \%$ had a problem in decision making, $49.22 \%$ did not have a problem in decision making and $13.42 \%$ were not sure that their ability of decision making had changed.

Disturbance in sleep patterns was found to be one of the consequences of depression ${ }^{15}$. Statistical evaluation of data obtained from the students who were having troubles with their sleep after starting the university education stated that $49.89 \%$ had no change in sleep, $20.58 \%$ slept more than usual, $29.53 \%$ slept less than usual. Statistical evaluation of data obtained from students who did not enjoy eating their food stated that $85.23 \%$ did not enjoy eating their food, $11.41 \%$ enjoyed eating their food and $3.36 \%$ were not sure. When the data was analysed categorically it was found that the age group 21-22 (22.8\%) had the maximum number of students who had an increase in their sleep and the age group Above 22 (59.3\%) had the maximum number of students had no change in their sleeping pattern.

Suicidal tendency and feeling of failure are some of the major consequences of depression ${ }^{14}$. When students were asked that, do they feel that everything that they have done has been a failure, it was found that $19.69 \%$ of students thought everything that they have done has been a failure, $70.25 \%$ did not feel the same and $10.07 \%$ were not sure how they felt. However, Statistical evaluation of data obtained from the students who thought about suicide since starting their university education stated that $9.6 \%$ of the students thought about suicide at least once i.e., $1.1 \%$ of students always thought about suicide, $1.8 \%$ of students thought about suicide more than twice, $1.3 \%$ students thought about suicide twice, $5.4 \%$ students thought about suicide once. While $90.4 \%$ of students never thought about suicide. When the data was analysed categorically it was found that the age group 17-18 was the group most venerable to suicidal thoughts and the age group Above 22 was the least venerable to suicidal thoughts. While the most responses where students thought that they had no future were from the age group 19-20 (17.9\%) whereas the maximum number of students who did not believe in the above-mentioned premise were from the age group of Above 22 (79.6\%).

\section{CONCLUSION}

Being a student is an important phase in a person's life. Especially college life is a vital time span. The vast majority of them are in their late adolescent age, physically getting mature, and psychologically unstable. They are undergoing various types of stress to study, to complete their assignments, to participate in various programs in the college. The stress can also be the result of the imbalance between the environment and demand. As per the study lead by us, the students were confronting issues in retaining things in which they were less interested, were facing socializing and sleep issues. Much of the participants also said they were not enjoying their food. $5 \%$ of participants had once thought of suicide. Certain factors like education counselling, parenting should be focused upon among students to decrease the prevalence of depression among youth.

\section{REFERENCES}

1. Pandya B, Deshpande R, Karani A. A Study on Impact of Academic Stress on MBA Students of Gujarat Technological University. Journal of Arts, Science \& Commerce. 2012; 3(3):80-85.

2. Singh M, Goel NK, Sharma MK, Bakshi RK. Prevalence of Depression, Anxiety and Stress among Students of Punjab University, Chandigarh. Natl J Community Med 2017; Vol 8(11):666-671.

3. Selye $H$. The Stress of Life. Revised edition, New York, McGraw-Hill, 1976:48.

4. Walter G, Soh N, Norgren Jaconelli S, Lampe L, Malhi G, Hunt G. Medical students' subjective ratings of stress levels and awareness of student support services about mental health. Postgraduate Medical Journal. 2013; 89(1052): 311-315.

5. Buchanan J. Prevention of Depression in the College Student Population: A Review of the Literature, Archives of Psychiatric Nursing. 2012;26(1):21-42.

6. Reavley N, Jorm A. Prevention and early intervention to improve mental health in higher education students: a review. Early Intervention in Psychiatry. 2010;4(2):132-142.

7. Castaldelli-Maia J, Martins S, Bhugra D, Machado M, Andrade $A$, Alexandrino-Silva $C$ et al. Does ragging play a role in medical student depression - Cause or effect? Journal of Affective Disorders. 2012;139(3):291-297.

8. Marcus M, Yasamy MT, van Ommeren M, Chisholm D, Saxena S. Depression, A Global Public Health Concern. World Health Organization, Geneva. 2017:6-8

9. Acharya Pandey R, Chalise H. Self-Esteem and Academic Stress among Nursing Students, Kathmandu University Medical Journal. 2015;13(4):298-302. 
10. Moir F, Yielder J, Sanson J, Chen Y. Depression in medical students: current insights. Advances in Medical Education and Practice. 2018;9:323-333.

11. Kaur S, Deepti S.S, Lal M. Prevalence and Correlates of Depression among College going students of District Amritsar, India. International Research Journal of Medical Sciences. 2014; 2(11):5-9.

12. Iyer K, Khan Z. Depression - A Review. Research Journal of Recent Sciences. 2012; 1(4):79-87.

13. Rajkumar E, Sooraj KV, Sandeep BH, Harish C. Psychosocial Problems among Students of Central
University of Karnataka: A Comparative Study. Int J Sci Stud 2015;3(9):44-47.

14. American Psychiatric Association: Practice Guideline for the Treatment of Patients With Major Depressive Disorder, Third Edition. American Psychiatric Association. Arlington, VA. 2010. Available from URL: http://psychiatryonline.org/content.aspx?bookid $=28$ \&sectionid=1667485. As accessed 2013-12-20.

15. Who.int. 2021. Depression. [online] Available at: <https://www.who.int/healthtopics/depression\#tab=tab_1> [Accessed 18 February 2021].

Source of Support: The author(s) received no financial support for the research, authorship, and/or publication of this article.

Conflict of Interest: The author(s) declared no potential conflicts of interest with respect to the research, authorship, and/or publication of this article.

For any question relates to this article, please reach us at: globalresearchonline@rediffmail.com New manuscripts for publication can be submitted at: submit@globalresearchonline.net and submit_ijpsrr@rediffmail.com 